\title{
A linguagem escrita: uma história de sua pré-história na infância
}

\author{
Ana Maria Esteves Bortolanza* \\ Selma Aparecida Ferreira da Costa ${ }^{* *}$
}

\section{Resumo}

Este artigo apresenta parte de uma pesquisa cujo objetivo é explicar o processo de apropriação da cultura escrita pelas crianças na educação infantil, de acordo com a organização das atividades de escrita que lhes são propiciadas no ambiente escolar. Para compreender esse processo foi realizado um experimento pedagógico em uma turma de crianças de cinco anos de idade, numa escola pública, na cidade de Uberaba/MG. A dimensão teórico-metodológica deste estudo fundamenta-se nos princípios do desenvolvimento humano apresentados pela Teoria Histórico-Cultural, que traz em seu bojo a Teoria da Atividade e a importância da mediação. A proposta de uma intervenção didática, realizada por meio do experimento pedagógico, objetivou descrever, compreender e explicar o processo de apropriação da cultura escrita a partir da realização de atividades organizadas de maneira a criar condições favoráveis para o desenvolvimento do processo em suas particularidades constitutivas, para que fosse possível provocar e observar os diferentes estágios por que passam a criança na pré-história de sua escrita. Ao delinear os caminhos percorridos por ela neste processo, oportunizou as condições necessárias para utilização da escrita em sua funcionalidade social, valendo-se da atividade guia do desenvolvimento, nesta faixa etária, que é a brincadeira de papeis sociais. A análise dos dados apontou indícios de que uma ação pedagógica, devidamente planejada e mediada, cria as circunstâncias que possibilitam a efetivação do processo de apropriação da escrita em sua funcionalidade social, propiciando uma mudança qualitativa na relação da criança com esse tipo de linguagem, pois ela apresenta a necessidade de escrever.

Palavras-chave: Apropriação da Cultura Escrita. Pré-história da escrita. Educação Infantil.

\footnotetext{
* Doutora em Educação pela Universidade Estadual Paulista Júlio de Mesquita Filho (UNESP). Professora da Universidade de Uberaba (UNIUBE).

** Mestre em Educação pela Universidade de Uberaba (UNIUBE). Doutoranda em Educação pela Universidade Estadual Paulista Júlio de Mesquita Filho (UNESP). Professora Formadora da Secretaria Municipal de Educação de Uberaba.
} 


\section{Introdução}

Este artigo apresenta parte de uma pesquisa realizada em 2014, cujo estudo enfatizou o processo de apropriação da escrita pela criança na educação infantil, buscando retratar a pré-história de sua escrita por meio dos diferentes estágios percorridos por ela na assimilação da linguagem escrita, de acordo com as atividades que lhes são propiciadas no ambiente escolar.

Como fonte de sustentação teórica deste estudo, buscamos na Teoria Histórico-Cultural os principais conceitos explicativos do desenvolvimento, fundamentados nas premissas: a natureza social do desenvolvimento psíquico e seu caráter interfuncional e o papel fundamental dos signos, como artefatos semióticos propulsores do desenvolvimento da criança. A partir desta concepção teórica, estruturamos o estudo nas contribuições de Vigotski (2000, 2008, 2010), especificamente nos conceitos primordiais deste autor, como mediação e desenvolvimento das funções psíquicas superiores, a linguagem e seu papel fundamental no desenvolvimento humano, os signos como ferramentas para apropriação e a significação cultural. Fundamentamo-nos, ainda, na contribuição da chamada "Escola de Vigotski": Leontiev (1988), que nos traz as bases da Teoria da Atividade e, particularmente, o conceito de cultura. Luria (1987, 1994), que aborda os caminhos que compõem a pré-história da escrita, delineando as origens dessa forma de linguagem em sua gênese, no período pré-escolar. E, ainda, nos escritos de Mukhina (1996), que se constituíram como referências teóricas para definirmos o experimento pedagógico, embasado no método histórico-genético de Vigotski, o qual nos permite conhecer as etapas de desenvolvimento infantil em idade pré-escolar em suas relações com o entorno da criança.

A perspectiva de desenvolvimento humano proposta pela Teoria Histórico-Cultural vem trazer importantes contribuições científicas no sentido de explicar qual a origem e como efetivamente se desenvolvem as funções superiores no homem. Vigotski (2000) nos mostra que para entendermos as funções psíquicas superiores em toda sua complexidade devemos considerá-las como sendo de origem histórica e social, ou seja, elas nascem e se desenvolvem nas relações sociais estabelecidas na vida em sociedade. A criança vai se apropriando da cultura historicamente construída pela humanidade, num processo mediado pela linguagem como signos semióticos.

A pesquisa foi desenvolvida em uma escola municipal de Uberaba, estado de Minas Gerais, no período de maio a julho de 2013 e consistiu-se, na primeira fase, em observações das atividades desenvolvidas pela professora com a escrita, seguindo-se de uma atividade exploratória para 
conhecermos o que pensam as crianças sobre a escrita. Na segunda fase da pesquisa desenvolvemos o experimento pedagógico que nos propiciou provocar o fenômeno a ser estudado em suas particularidades e dinamicidade histórica.

Tendo em vista os objetivos que pretendemos alcançar, nosso foco são as atividades pedagógicas, portanto, trata-se de um experimento de cunho pedagógico, centrado na forma de organizar e desenvolver a atividade na educação infantil, de modo a promover o desenvolvimento das crianças. Ainda que possua suas raízes genéticas nos experimentos de Vigotski, que estão voltados para a compreensão dos processos de formação das funções psíquicas superiores, optamos, neste estudo, pelo experimento pedagógico como procedimento metodológico voltado para a atividade das crianças.

Mukhina (1996, p. 21-22) faz uma distinção entre o experimento formativo e o pedagógico e os caracteriza, ao esclarecer que:

Os psicólogos soviéticos empregam amplamente o experimento formativo. Sua particularidade consiste em que o método utilizado para estudar os processos e qualidades psíquicos é ao mesmo tempo um ensinamento, destinado a formar ou aperfeiçoar essas qualidades e processos psíquicos. [...] O experimento formativo na pesquisa psicológica não deve ser confundido com o experimento pedagógico, destinado a comprovar a eficácia dos novos programas e métodos do ensino e da educação. Externamente são parecidos; nos dois casos ensina-se às crianças algo novo e o resultado positivo do ensino confirma suposições prévias. A diferença consiste no caráter das suposições; o psicólogo faz suposições sobre os processos, qualidades e traços psíquicos da personalidade no processo de desenvolvimento da criança; ao pedagogo interessam os caminhos para obter bons resultados no ensino e na educação de crianças.

$\mathrm{O}$ experimento pedagógico que desenvolvemos tem seu foco na atividade do brincar para apropriação da cultura escrita em sua funcionalidade e na maneira como o professor organiza o ensino intencional. Não tem, portanto, a pretensão de focar as novas formações psicológicas dos sujeitos pesquisados.

O experimento pedagógico desenvolvido visou criar uma situação de ensino especialmente organizada para atender às necessidades da pesquisa, no sentido de criarmos condições específicas para realizá-lo, sabendo de antemão que todo o experimento possui certas limitações no contexto em que é desenvolvido. Por tratar-se de uma situação artificial de ensino desenvolvida em curto espaço de tempo pela pesquisadora, consequentemente, traz as marcas de sua provisoriedade.

O objetivo central do experimento pedagógico não é propor um método e testá-lo com as crianças. É, sobretudo, organizar o ensino e as atividades para investigar e explicar os fundamentos de 
tal organização, ou seja, visa fundamentalmente compreender a natureza do processo pesquisado, e não se atém aos possíveis resultados obtidos.

Diante do desafio de explicar como as crianças se inserem no universo da cultura escrita, que significados elas lhe atribuem, e, sobretudo, compreender a passagem de uma forma de representação a outra na dinâmica processual da pré-história de sua escrita, o experimento pedagógico foi desenvolvido por meio de três fases inter-relacionadas: planejamento das atividades de intervenção em campo, execução das atividades planejadas e análise do processo de desenvolvimento do experimento.

As unidades de análise empregadas correspondem à linguagem oral, aos gestos, às relações entre as crianças na realização das atividades e ao grau de envolvimento destas no processo como um todo.

\section{O papel da linguagem no desenvolvimento humano}

Dentre todos os sistemas de signos criados pelo homem, a linguagem se constitui como fundamental no processo de desenvolvimento humano, sem a qual não seriam possíveis todos os avanços culturais obtidos pela humanidade. É por meio da linguagem que o homem se comunica, organiza seu pensamento, compartilha e registra conhecimentos.

Quando falamos sobre a importância da linguagem para o desenvolvimento humano, referimonos à linguagem oral, que representa a forma de comunicação entre as pessoas, e também à linguagem escrita, por sua propriedade de converter-se em meio de expressão de ideias, e, ainda, como condutora do desenvolvimento do pensamento. Num aspecto mais profundo, para explicação do comportamento humano mediado por signos, a linguagem inter-relaciona os estímulos externos e internos, que são significados pelo indivíduo, provocando novas ações e reações nos referidos estímulos.

Afirma Vigotski (2000, p. 86-87, tradução nossa):

O homem, portanto, tem criado um aparato de sinais, um sistema de estímulos artificiais condicionados, com ajuda dos quais ele cria quaisquer conexões artificiais e provoca reações necessárias do organismo. Se compararmos, seguindo Pavlov, a parte externa dos grandes hemisférios com um grandioso sistema de sinais, poderíamos dizer que o homem criou a chave desse quadro, do grandioso sistema de sinais da linguagem. Com a ajuda dessa chave domina desde fora a atividade externa e dirige o comportamento ${ }^{1}$.

Pela linguagem, o homem influencia externamente o outro e internamente a si mesmo. Esse processo se realiza externamente, por meio da comunicação oral e escrita, pelo intercâmbio de 
informações e, internamente, pela posterior propriedade de converter-se em meio de orientação das operações intelectuais. Assim, podemos dizer que a criança se apropria da cultura humana por meio da atividade, mediada por signos, processo em que a linguagem se configura como fundamental. Esse procedimento precisa ser devidamente estruturado, por meio de condições que permitam uma intervenção docente planejada e organizada, como deve ser o ensino intencional na escola de educação infantil.

Para explicar a formação do vínculo entre o pensamento e a palavra, seja ela oral ou não, bem como seu desenvolvimento, Vigotski (2010, p. 398) apresenta o significado da palavra como sendo a unidade indecomponível entre ambos os processos e afirma: "o significado da palavra é, ao mesmo tempo, um fenômeno de discurso e intelectual". É importante ressaltar que o significado da palavra se modifica no processo de desenvolvimento da criança, assim como se modificam também os diferentes modos de funcionamento do próprio pensamento.

A compreensão quanto ao papel funcional do significado da palavra no ato do pensamento, passa pelo entendimento do processo que inter-relaciona o significado da palavra na ação de pensar, ou seja, como no pensamento verbalizado a criança opera com a palavra para auxiliá-la na resolução de tarefas que lhes são propiciadas. Cabe ressaltar que a relação entre pensamento e palavra, como processo dialético, passa por diferentes fases relacionadas não só à faixa etária da criança, mas, sobretudo, à capacidade que ela desenvolve de utilizar a palavra para orientar sua atenção, sua memória, nas diferentes operações que realiza.

A palavra, enquanto signo, pode ser utilizada de diferentes maneiras, como meio de comunicação e organização da ação para a concretização das operações intelectuais necessárias. É justamente a observação do modo como a criança utiliza a palavra nessas circunstâncias que nos permite compreender em que estágio de desenvolvimento intelectual ela se encontra, bem como nos possibilita obter indícios que apontem para a explicação do processo de formação dos conceitos na criança, tornando possível compreender como ela se vale da linguagem para organizar voluntariamente seu pensamento.

Neste sentido Vigotski (2010, p. 174) acentua o caráter mediador da linguagem no desenvolvimento das funções psíquicas superiores, ao mostrar que:

A evolução do inferior para o superior não se dá pelo crescimento quantitativo dos vínculos, mas de novas formações qualitativas; entre outras coisas, a linguagem, que é um dos momentos fundamentais na construção das formas superiores de atividade intelectual, insere-se não por via associativa como função que transcorre paralelamente, mas por via funcional como meio racionalmente utilizado. 
$\mathrm{O}$ autor vincula a linguagem como signo à formação qualitativa dos processos intelectuais superiores. À medida que se desenvolve, a criança vai tornando-se capaz de utilizar a linguagem de maneira funcional, como instrumento fundamental para comunicar-se, expressar suas ideias, organizar seu próprio pensamento e, sobretudo, como meio auxiliar no desenvolvimento de suas ações, na atividade guia.

Um fato importante a ser considerado é que o desenvolvimento mental de uma criança é regulado pelo controle de sua atividade guia. É o que Leontiev (1988, p. 122) chama de: “[...] atividade principal aquela em conexão com a qual ocorrem as mais importantes mudanças no desenvolvimento psíquico da criança e dentro da qual se desenvolvem processos psíquicos que preparam o caminho de transição da criança para um novo e mais elevado nível de desenvolvimento”.

A atividade representa um papel primordial no desenvolvimento do indivíduo em seus estágios de desenvolvimento. No entanto, ela não pode ser concebida de forma mecânica, isolada do meio social. Existe um conteúdo preciso que a compõe e que coincide, mas não de maneira determinante e imutável, com a idade cronológica da criança. No período da infância pré-escolar, o jogo de papéis sociais é a atividade guia, pois a criança já superou o estágio da simples manipulação dos objetos e começam a surgir novas necessidades e formas de ela relacionar-se com o mundo.

A utilização da linguagem, como instrumento mediador das funções psíquicas superiores, confere a criança uma amplitude funcional, que abrange a utilização da linguagem como auxiliar da memória e como forma peculiar de representação. No plano filogenético, as novas funções da linguagem que surgiram ao longo da evolução humana permitiram o desenvolvimento de uma forma específica de linguagem que auxilia a memorização e o registro das aquisições históricas: a escrita.

\section{A pré-história da escrita no desenvolvimento da escrita infantil}

Para compreendermos o processo de apropriação da cultura escrita no período pré-escolar, é fundamental identificarmos as suas origens nas relações que a criança vai gradativamente estabelecendo com a escrita. Entendemos que o processo de apropriação da cultura escrita não se inicia no momento em que a criança entra na escola e começa a aprender a escrever, mas sim com o significado que o objeto escrita tem para ela e qual o sentido de sua utilização, pois mesmo antes de entrar na escola ela já experimenta situações de uso deste recurso cultural. 
O processo de apropriação só pode ser compreendido como processo histórico, ou seja, de que maneira a criança apropria-se dos conhecimentos culturais, pois, como afirma Vigotski (2000, p. 184):

O domínio da linguagem escrita significa para a criança dominar um sistema de signos simbólicos extremamente complexo. [...] o domínio deste sistema complexo não pode realizar-se por uma via exclusivamente mecânica, desde fora, por meio de uma simples pronunciação, de uma aprendizagem artificial. [...] O domínio da linguagem escrita é, na realidade, o resultado de um largo desenvolvimento das funções psíquicas superiores do comportamento infantil. [...] O desenvolvimento da linguagem escrita não segue uma linha única, nem conserva nada parecido a uma sucessão de formas. $\mathrm{Na}$ história do desenvolvimento da linguagem escrita na criança nos encontramos com as metamorfoses mais inesperadas, quer dizer, com a transformação de umas formas de linguagem escrita em outras.

Nesse enfoque é necessário considerar as involuções decorrentes do desenvolvimento do próprio processo, as interrupções, as transformações, às vezes imperceptíveis, de uma forma de representação em outra. Já a aprendizagem artificial está relacionada à apreensão do código alfabético como a forma ideal para se apropriar da cultura escrita, desconsiderando sua funcionalidade social.

É esse o foco do autor ao estudar a pré-história da linguagem escrita para conhecer e explicar os meios pelos quais este sistema externo de símbolos e signos se converte em uma função psíquica da própria criança, ou ainda como "a linguagem escrita da humanidade se converte em linguagem escrita da criança" (VIGOTSKI, 2000, p. 185).

No texto "A Pré-História da Escrita da Criança", Vigotski (2000) apresenta as ligações genéticas entre o gesto, o desenho, o jogo infantil e a escrita. Em suas investigações, o autor mostra claramente como esse processo se desenvolve, ao evidenciar que o gesto é o embrião da futura escrita, pois, inicialmente, as garatujas e os desenhos das crianças representam seus gestos materializados. Posteriormente, no decorrer do processo evolutivo da pré-história da escrita, o desenho irá se converter em signo, pois a criança se utilizará dele para representar uma ideia. O segundo momento de ligação genética entre o gesto e a escrita é representado pelos jogos infantis, nos quais a criança confere significado ao objeto que utiliza com uma função simbólica assumida que determina a função de signo.

Buscando entender e explicar o processo de apropriação da escrita do seu ponto de vista histórico-cultural, Luria (1994, p. 144) desenvolve um estudo fecundo sobre as origens da escrita no período pré-escolar e afirma que na:

Pré-história individual a criança já tinha desenvolvido por si mesma um certo número de técnicas primitivas, semelhantes àquilo que chamamos escrita e capazes de, até mesmo, desempenhar funções semelhantes, mas que são perdidas assim que a escola proporciona à criança um sistema de signos padronizados e econômico, culturalmente 
elaborado. Estas técnicas primitivas, porém, serviram como estágios necessários ao longo do caminho.

É fundamental considerar na educação infantil as técnicas primitivas da escrita que a criança utiliza para se comunicar, que são vivenciadas por ela, muito antes do seu ingresso na escola, visto que a escrita é uma criação cultural presente no meio social em que ela vive, desde seu nascimento. Nesta perspectiva o professor precisa conhecer a pré-história do desenvolvimento da linguagem escrita, do gesto às brincadeiras, que possibilitarão à criança desenvolver, mais tarde, a escrita simbólica. Tais estágios estão diretamente relacionados com a identificação dos motivos que levam uma criança a escrever e quais são os fatores que habilitam a passagem de um estágio para outro.

Inicialmente a criança precisa estabelecer uma relação funcional com a escrita, ou seja, compreender que a escrita possui uma função social, que o emprego de signos auxiliares, como linhas, letras, pontos, entre outros, permitem registrar uma ideia e, posteriormente, recordar o que fora escrito. Luria (1994, p. 146) define a escrita como "uma técnica auxiliar usada para fins psicológicos; a escrita constitui o uso funcional de linhas, pontos e outros signos para recordar e transmitir ideias e conceito". Essa relação funcional com a escrita é estabelecida pela criança por meio da atividade, que nessa faixa etária é a brincadeira de papeis sociais.

Leontiev (1988) define a atividade como um processo de relações estabelecidas entre o homem e o mundo ao seu redor, que se desenvolve por meio de ações e operações, cujo objetivo deve satisfazer a uma necessidade. $\mathrm{O}$ autor analisa a atividade como sendo "processos psicologicamente caracterizados por aquilo a que o processo, como um todo, se dirige (seu objeto), coincidindo sempre com o objetivo que estimula o sujeito a executar esta atividade, isto é, o motivo" (LEONTIEV, 1988, p. 68).

Se o conteúdo proposto, em uma determinada atividade, estimula o sujeito a agir de maneira intencionalmente estruturada para atingir um objetivo que satisfaça uma necessidade interna sua e, por isso, coincida com o motivo de sua ação, configura-se como uma atividade, sem nos esquecermos da característica psicológica fundamental que dirige todo o processo: a motivação. O motivo como motor propulsor da ação está imbuído de emoções e sentimentos que fazem o indivíduo sentir-se estimulado e se empenhar, dar o melhor de si para alcançar o objetivo desejado. Portanto, motivação e ação não estão dissociadas. Ao contrário, são elas que direcionam a concretização plena do processo como um todo. A própria necessidade é um gerador de motivação que impulsiona para a objetivação da ação e surge das relações do indivíduo com o meio social, convertendo-se em um objetivo a ser alcançado.

Para a apropriação da escrita pelas crianças, é preciso que tal necessidade seja criada, que a criança sinta vontade e necessite utilizar-se da escrita em toda a sua funcionalidade social. Logo, ao 
organizar atividades que propiciem o desenvolvimento das funções psíquicas superiores, é imprescindível tomarmos como ponto de partida as necessidades basilares da criança em cada etapa do seu desenvolvimento.

Ocorre que as necessidades internas vão se transformando ao longo da ontogênese, isto é, na história do indivíduo; por conseguinte, modificam-se os motivos que o impelem a agir. É sobre essa base psicológica que vão se concretizando as mudanças na atividade guia e, consequentemente, a passagem de um estágio de desenvolvimento a outro. Sendo assim, pensar a apropriação da escrita na educação infantil, para além da aprendizagem motora do traçar as letras, palavras ou frases, implica desde sua origem a elaboração de significados e sentidos que passam pela atividade externa e interna da criança. Para que se apropriem das máximas qualidades, as atividades com as crianças devem ser planejadas, e o trabalho educativo do professor precisa ser organizado para antecipar seu desenvolvimento, segundo suas necessidades e possibilidades.

Identificar os sentidos que as crianças atribuem à escrita e as implicações diretas que tais sentidos exercem sobre o processo de apropriação desse objeto é necessário para compreendermos como elas se relacionam com esta atividade. Se na escola de educação infantil, a concepção de escrita está associada a uma prática alienante e alienadora, sua apropriação só poderá resultar em atos fragmentados de escrita, uma vez que se resumirá a algo mecânico, esvaziado de significado, desconectado da realidade na qual a escrita se insere, passando a se constituir apenas em um treinamento do código alfabético. Como afirma Vigotski (2010), a escrita não é uma simples tradução da linguagem falada para signos escritos e apreendê-la não é apenas uma questão de técnica.

As atividades desenvolvidas com as crianças, na pesquisa, apontaram a ligação genética existente entre o gesto, o desenho e a brincadeira, como podemos constatar na análise a seguir, ao apresentarmos o caminho percorrido por elas no processo de apropriação da escrita, marcado por graduais etapas de diferenciação e utilização de símbolos

Compreendemos, nos estudos desenvolvidos por Vigotski (2000) e Luria (1994), que o desenvolvimento inicia-se com o gesto indicador, em seguida passa pelos rabiscos ou garatujas sem nenhuma relação com o significado, apenas uma imitação da atividade de escrita do adulto e, posteriormente, pelo desenho, que gradualmente vai ganhando atributos até se caracterizar como escrita pictográfica, pois, neste estágio, ocorre uma mudança significativa na relação da criança com a escrita: o desenho como símbolo apresenta traços que o relacionam ao significado e assim ele começa a refletir a ideia que a criança deseja expressar. 


\section{Os desenhos e o que as crianças dizem sobre eles}

A atividade desenvolvida teve como objetivo provocar, por meio do diálogo, uma situação que colocasse a criança diante de circunstâncias que lhe exigissem a utilização de um recurso gráfico de representação de uma ideia: o desenho.

Uma das atividades desenvolvidas durante o experimento consistiu em orientar as crianças a fazer um desenho que representasse a escrita. A unidade de análise utilizada nesta atividade foram as relações que as crianças estabeleceram com a escrita até então, propiciadas pelas experiências com este objeto cultural, tendo como fonte não só os desenhos feitos por elas, mas, sobretudo, os sentidos a eles atribuídos, nos diálogos das crianças com a pesquisadora.

Essa atividade foi realizada individualmente, para que cada criança pudesse expor sua ideia sem se deixar influenciar pelo que o outro havia falado ou desenhado. Assim que terminava de desenhar, a criança ia dizendo o que representou. O objetivo era verificar se as crianças desenhavam para além do que viam, isto é, se desenhavam significados que pudessem auxiliá-las na representação sobre a escrita.

O desenho abaixo, feito por Bryan, revelou a seguinte relação estabelecida com a escrita (Figura 1).

\section{Figura 1 - Desenho de Bryan}

Fonte: Acervo das autoras (22 maio 2013).

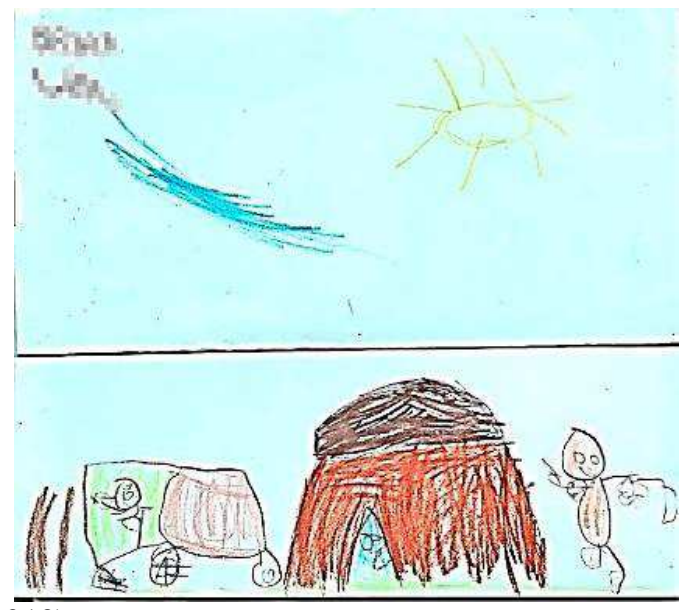

O desenho de Bryan (Figura 1) mostra uma casa, algo que parece ser um carro com alguém dirigindo, provavelmente duas pessoas no interior da casa e alguém fora. Temos a presença de uma nuvem, do sol e, à esquerda, o nome dele escrito em caixa alta, faltando uma letra; abaixo, as letras $u$, $b, r$. 
No diálogo que tivemos sobre seu desenho, ele diz: “Eu desenhei um caminhão, meu pai está dirigindo o caminhão. Esta é minha casa. Lá dentro está minha mãe, meu avô e minha irmã. Eu estou do lado de fora brincando. Aqui eu desenhei as nuvens e o sol. Aqui eu escrevi 'quase Uberaba".

Indagado pela pesquisadora por que "quase escreveu", ele respondeu: "Faltou o resto das letras. E aqui eu escrevi meu nome".

Bryan mostra que seu desenho tem significado, contém uma ideia, ou seja, seu desenho já representa signos simbólicos utilizados para expressar significados e relações subjetivas sobre a escrita. Isso se evidencia quando ele descreve o desenho da casa e das pessoas que ali habitam, apesar de não estarem claramente objetivadas no desenho. Apoiando-se no desenho, os significados atribuídos por ele demonstram ser esse momento um estágio fundamental para o desenvolvimento da escrita simbólica. Embora esta criança esteja aprendendo na escola de educação infantil que escrever é registrar o código alfabético, copiar no caderno letras que representam sons, nesta atividade o desenho foi empregado como uma linguagem de significados que antecede a apropriação da escrita simbólica em sua complexidade. Em sua pré-história de desenvolvimento da linguagem escrita, Bryan passa pelo desenho já.

Vigotski (2000) afirma ser o desenho uma etapa que precede a escrita, ao dizer que se trata de uma linguagem gráfica por sua função psicológica, uma espécie de relato gráfico, um tipo de linguagem escrita, mais linguagem que representação.

No percurso de desenvolvimento da escrita, a criança vai superando uma técnica primitiva em direção a outra mais elaborada, em que os recursos pictográficos vão se combinando com a escrita simbólica, pois a pictografia já não é suficiente para representar toda a ideia, como podemos verificar no desenho de Leila em relação à escrita (Figura 2).

Figura 2 - Desenho Leila

Fonte: Acervo das autoras (22 maio 2013).

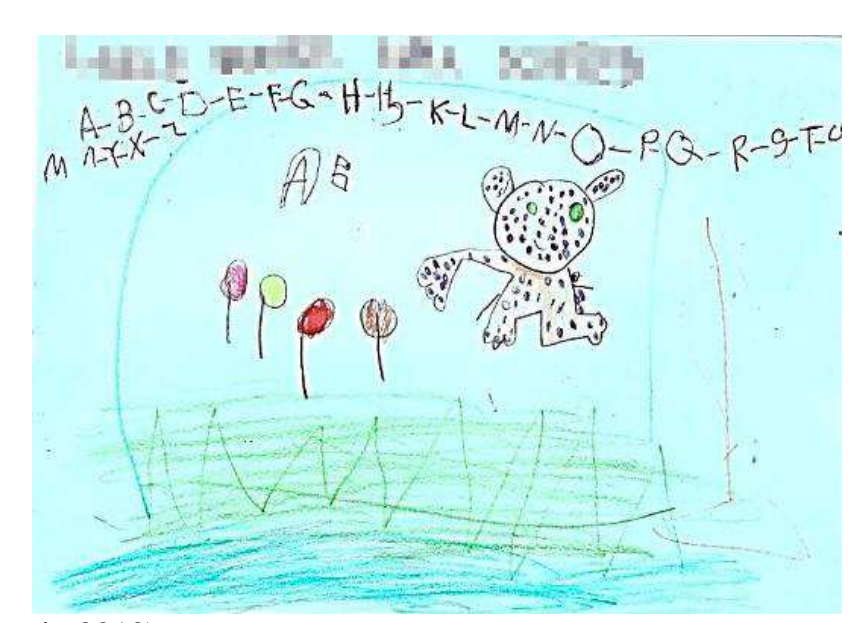


É possível ver em seu desenho que Leila utiliza uma combinação entre escrita gráfica culturalmente convencionada, ou seja, há uma combinação entre símbolos historicamente interpostos. Podemos concluir pelo descrito por Leila, a seguir

A escrita pra mim é as histórias. Eu desenhei a da onça e as uvas [A raposa e as uvas], $o$ ABC [alfabeto], que é pra eu escrever meu nome completo. Ele [seu nome] demora um pouquinho porque ele é muito grande...

Pesquisadora: E o que você escreveu aqui? [ao lado do desenho da onça]

Escrevi "a onça está com fome e quer pegar as uvas".

Observamos que Leila utiliza em seu desenho diferentes formas de representação: ela passa da escrita pictográfica para a a escrita simbólica arbitrária. Temos indícios que reforçam a tese de que a criança passa por diferentes estágios pré-históricos de elaboração da escrita, em que uma técnica vai superando a outra na medida em que emergem as necessidades de representação da ideia, mesmo que ela ainda não tenha compreendido o sentido e o mecanismo da utilização de marcas simbólicas. Leila parece perceber que uma das funções sociais da escrita é a representação da realidade por meio da escrita, ao se referir às histórias.

Nesse aspecto, nos assentamos nas colocações de Luria (1988, p. 188), que explica a origem e utilização dos signos pela criança, ao dizer que "não é a compreensão que gera o ato, mas é muito mais o ato que produz a compreensão", ou seja, a criança apropria-se dos conhecimentos sobre a escrita por meio de atos com a escrita. Os atos de escrita na educação infantil, precisam ser colocados em situações em que a criança possa se expressar sem recorrer à escrita convencional, que ela ainda não domina, possibilitando que ela assimile, prioritariamente, sua função social específica. Esta atividade pressupõe uma participação ativa do sujeito aprendiz sobre o objeto a ser apreendido para que possa tornar seu o conhecimento acumulado pelas gerações precedentes.

\section{A brincadeira: germe da futura escrita}

Retomemos a característica principal que determina a passagem de um estágio de desenvolvimento para outro, que é a mudança das necessidades e motivos, os quais impulsionam determinada atividade. Surgem necessidades e impulsos específicos, característicos da criança neste período, que não podem ser realizados imediatamente, em virtude de variados fatores, tais como as limitações física e psicológica da criança em relação ao adulto. A criança, então, se vê diante de um 
impasse: de um lado, tem que lidar com o surgimento de tais desejos irrealizáveis, entretanto, simultaneamente, traz em si a tendência para a realização imediata de seus desejos, característica da primeira infância.

É neste momento contraditório que a brincadeira de papéis sociais surge como atividade que permite à criança a realização de uma situação imaginária de seus desejos irrealizáveis. Porém, tais desejos não devem ser entendidos como simples impulsos incontroláveis, mas sim como impulsos provenientes de suas relações afetivas com os fenômenos sociais que a circundam.

Pela brincadeira, a criança age sobre o mundo e, ao mesmo tempo, assimila os padrões comportamentais da sociedade na qual está inserida, reproduzindo-os em suas ações lúdicas na atividade do brincar, o que representa um momento muito importante de delineamento de sua personalidade.

Vigotski (2008), em seu texto A Brincadeira e seu Papel no Desenvolvimento Psíquico da Criança, aponta a importância crucial da brincadeira como propulsora do desenvolvimento infantil da criança na idade pré-escolar, ao relacioná-la com a formação das funções da consciência, tais como a imaginação, a personalidade, a afetividade, a percepção e a preparação para o pensamento abstrato. Por meio da brincadeira, a criança cria uma situação imaginária que lhe permite vivenciar determinado desejo não realizado e assim começa a dominar o sistema das relações do adulto.

A essência da criação dessa situação imaginária consiste na possibilidade que ela propicia à criança de representar um papel social da vida adulta. O cerne dessa situação fictícia está no fato de, na brincadeira, o objeto mudar sua significação e as ações reconstruídas com ele pela criança tornarem-se representações abreviadas das ações reais do adulto. Isso provoca mudanças no pensamento da criança, pois, pela primeira vez, ela consegue separar os campos visual e semântico. Assim, passa a agir de acordo com o que tem em mente e não com o que vê. Esse é um critério fundamental que eleva a brincadeira à categoria de atividade guia na idade pré-escolar, pois permite que a criança separe a ideia do objeto, fazendo com que sua ação seja desencadeada pela ideia, pelo significado, e não pelo objeto em si.

A mudança no comportamento da criança proporcionada pela realização da atividade guia, neste estágio do desenvolvimento, pode ser evidenciada pela realização de uma atividade do experimento pedagógico, a qual denominamos: Brincando de ser professor. O objetivo foi permitir, por meio da brincadeira de papéis, que as crianças realizassem a atividade utilizando a escrita como recurso mnemônico, visto que esta é uma de suas funções primordiais. 
A realização da atividade foi dividida em dois momentos. No primeiro, a pesquisadora simulou uma situação imaginária na qual as crianças foram incentivadas a escrever um bilhete para suas mães, contendo os seguintes dizeres: "Mamãe, tenho que trazer um portador de texto para a escola. Pode ser livro, jornal, gibi, bíblia ou qualquer outro. Assinado: professora Selma" (12 jun. 2013). O enunciado do bilhete foi ditado para que a criança, no papel social de aluno, registrasse a ideia conforme suas possibilidades; em seguida, foi solicitado que lesse o que havia escrito. Observamos se as crianças utilizaram signos que as auxiliassem na recordação do conteúdo da mensagem.

As crianças, neste estágio de desenvolvimento, expressam sua fala interior em voz alta, por isso, ao mesmo tempo em que escreviam, iam falando para si a mensagem que desejavam transmitir. Assim que terminaram a escrita da mensagem, leram o que escreveram. A leitura foi comparada com sua ideia original, que havia sido registrada pela pesquisadora na lousa. Todo o desenvolvimento da atividade foi audiografado e fotografado.

A categoria de análise utilizada nesta atividade foi a utilização da escrita como recurso mnemônico. De acordo com Vigotski (2000), é o próprio homem quem cria os estímulos que determinam suas reações e utiliza esses estímulos como meios para dominar sua conduta e dos seus semelhantes. Então, no experimento pedagógico, quisemos instigar nas crianças a necessidade de utilizar a escrita como forma de se comunicarem e, simultaneamente, de significarem a escrita como um instrumento auxiliar de sua memória.

A ação externa de representação de uma ideia é guiada por ações internas, visto que, por trás da mão que escreve uma mensagem, está um cérebro que pensa e dirige todo o processo. Nessa perspectiva, então, os sujeitos do estudo, ainda não alfabetizados, tiveram como desafio registrar por meio de sinais gráficos a ideia desejada, tendo em conta que tais sinais gráficos deveriam ter a função de relembrar o conteúdo da ideia proposta. A escrita de Alex se materializou da seguinte maneira, conforme a Figura 3.

Figura 3 - Alex no papel de aluno

Fonte: Acervo das autoras (12 jun. 2013).

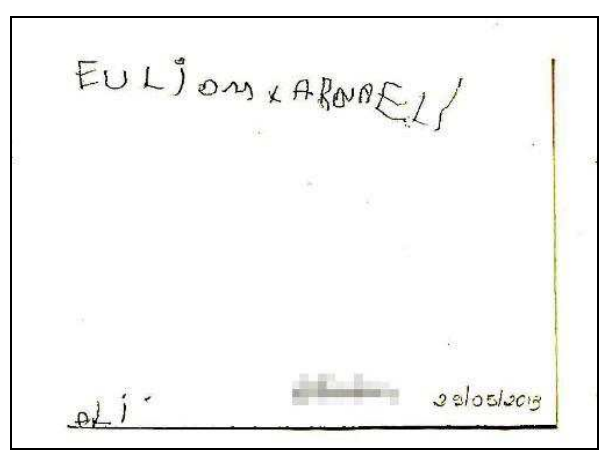


No primeiro momento da atividade, Alex utilizou-se de letras para registrar suas ideias, pois já se apropriara do conhecimento culturalmente posto de que utilizamos as letras como marcas convencionais da escrita para escrever. No entanto, não se apropriou de tais marcas para auxiliá-lo a recordar o conteúdo expresso. Apenas se lembrava de algumas palavras da mensagem: "mamãe", "livros", "gibi".

Entendemos que Alex não usou a escrita como função mnemônica e, portanto, não a considera como sendo um meio auxiliar da memória; ele registra letras aleatoriamente para imitar uma ação do adulto. $\mathrm{O}$ fato de utilizar letras para escrever corresponde ao estágio primário da escrita, à fase das garatujas, já que ele não domina a escrita convencionalmente representada, como ficou evidenciado no registro escrito.

Se nos valêssemos dos métodos que relacionam grafema/fonema para descobrir em que fase da pré-história de sua escrita essa criança está, não seria possível compreendermos as especificidades engendradas neste processo de apropriação da escrita, pois no desenvolvimento de uma atividade é preciso considerar o lugar que a criança ocupa na escala social, o qual determina de forma direta seu comportamento e reflete no resultado de suas ações.

No ensino, a criança, na posição de aprendiz, pensa e age de determinada maneira, pois todo o processo está sendo conduzido pelo professor, que é o organizador do trabalho educativo. Isso quer dizer que, no primeiro momento de realização desta atividade, em que a pesquisadora assumiu o papel da professora, os dados apontaram indícios de que a criança se portara psicologicamente de maneira semelhante ao que se porta na sala, mas com um diferencial muito importante: o desafio posto pela pesquisadora, de partir de uma necessidade da escrita como recurso mnemônico para se lembrar de algo, e não apenas de fazer cópia de palavras descontextualizadas. Isso ocasionou uma forma peculiar de representação da escrita, que revelou a utilização indiscriminada de letras, pois esta criança sabe que para escrever utilizamos marcas convencionais.

Num segundo momento, as crianças foram motivadas a participar de uma brincadeira em que os papéis sociais assumidos se inverteriam, ou seja, elas representariam o papel da professora e a pesquisadora seria a aluna. No diálogo com elas, a pesquisadora simulou uma situação na qual aconteceria uma festa. Durante a realização da atividade, assumindo o papel de professor, que neste momento estavam representando, as crianças deveriam escrever um convite aos pais, pois haveria distribuição de brinquedos, cachorro-quente, sorvete, guaraná, conteúdo sugerido pelas próprias crianças durante o planejamento da atividade. O convite foi escrito na lousa pelas crianças e a ideia que 
elas expressaram por meio da linguagem oral foi registrada fielmente pela pesquisadora em seu diário de campo.

Neste momento da atividade, em que os papeis sociais foram invertidos, ou seja, na situação imaginária em que cada uma das crianças sujeitos da pesquisa ocupou o lugar da professora, suas ações também se modificaram.

Trazemos para análise o papel que uma das crianças assumiu na atividade. Alex, uma das crianças sujeitos da pesquisa, utilizou a escrita para registrar a ideia desejada, como podemos ver na figura 4.

Figura 4 - Escrita de Alex no papel de professor

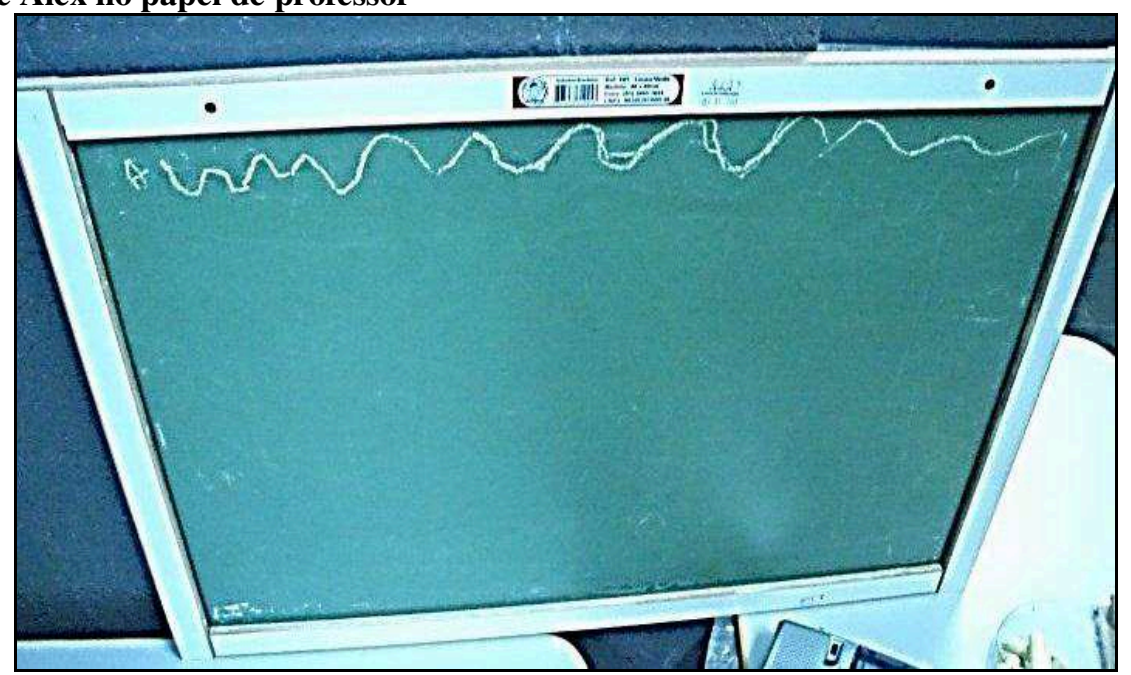

Fonte: Acervo das autoras (12jun. 2013).

Podemos inferir que a relação da criança com o objeto escrita modificou-se; o próprio significado da escrita para a criança se alterou, pois o papel assumido por ela na brincadeira mudou, o que lhe exigiu uma mudança de atitude na realização da atividade. Para ela, tratava-se de imitar a ação do adulto, e não de utilizar a escrita para representar uma ideia ou ainda como recurso auxiliar de sua memória. Para isso, ela utilizou uma forma peculiar de representação, correspondente às garatujas, explicitando com seu gesto a imitação da ação do professor.

A posição social que ocupou Alex na brincadeira influenciou diretamente sua relação com o objeto da atividade, diante do duplo desafio psicológico de ter que escrever a mensagem e, ainda, a responsabilidade de "dominar" a técnica da escrita para ensiná-la, pois neste momento ele era o professor. Alex retornou à utilização indiferenciada de signos, característica do desenvolvimento da pré-história da linguagem escrita nessa idade. O primeiro momento da pré-história da escrita se refere 
às garatujas e aos desenhos das crianças, que, de acordo com Vigotski (2000), em seu processo inicial, nada mais são que a representação do gesto. A criança assinala graficamente o que deseja demonstrar pelo gesto, conferindo a essa representação significação.

\section{Considerações finais}

A busca pela compreensão da maneira como se desenvolve o complexo processo de apropriação da cultura e, sobretudo, a trajetória histórica do desenvolvimento da linguagem escrita das crianças constituíram a trama sobre a qual nos debruçamos. No processo de pesquisa, as atividades do experimento pedagógico mostraram que a escola de Educação Infantil precisa criar na criança a necessidade de apropriação da cultura escrita, utilizando-se para isso da atividade guia - a brincadeira neste estágio do desenvolvimento humano.

Ao serem colocadas em atividades com a cultura escrita, por meio das quais assumiram um papel social e agiram sobre o objeto escrita, as crianças demonstraram interesse e envolvimento psicológico, à medida que o papel assumido na brincadeira exigiu delas determinado tipo de comportamento, favorecendo o desenvolvimento de suas funções psíquicas superiores, como a atenção, a concentração, a imaginação e a ação voluntária.

Sabemos que as crianças atribuem significado à escrita em conformidade com as experiências vivenciadas por elas em seu entorno social, uma vez que já se relacionam com a cultura escrita desde os primeiros anos de vida. Portanto, atribuem a ela significados no desenvolvimento de sua pré-história da linguagem escrita.

Contudo, as novas formas de interação com a escrita, propiciadas pelas atividades do desenho e da brincadeira de papeis sociais desenvolvidas com as crianças participantes do estudo, proporcionaram uma ressignificação deste objeto cultural, planejadas e organizadas pela pesquisadora, por meio de atividades significativas com a escrita em sua funcionalidade social. O que as crianças demonstraram de particular em seus gestos e atos de escrita guarda relação direta com a concepção de desenvolvimento da pré-história da linguagem escrita, apresentada por Vigotski e Luria.

Estas atividades desenvolvidas no experimento pedagógico mostraram que nas etapas de diferenciação e utilização de signos, experimentadas pelas crianças durante a pré-história de sua escrita, o que efetivamente se modifica é sua relação com a escrita, sendo o significado a estrutura que permitirá a superação de uma técnica por outra. 
Tais atividades foram organizadas de maneira a criar nas crianças, participantes da pesquisa, a necessidade e os motivos para apropriarem-se do mundo da escrita, por meio da brincadeira de papeis sociais. Tendo realizado ações concretas que permitiram diferenciar e relacionar os escritos a seus significados, as crianças demonstraram haver separado a palavra do objeto, pois num primeiro momento, ao brincar, valeram-se da escrita para imitar a ação do adulto. Posteriormente, ao modificar o papel desempenhado, passaram a utilizar a escrita como representação gráfica, empregando para isso marcas culturalmente convencionadas, como o código alfabético.

No desenvolvimento das atividades, as crianças demonstraram compreender o objetivo que as orientava nas atividades desenvolvidas; isso fez com que elas se esforçassem para enfrentar o desafio que lhes fora posto e, motivadas, buscaram resolver o problema: significar a escrita em seus usos. Isso mostra que a escrita, em sua complexidade, precisa estar presente na atividade do brincar para que a criança se aproprie de sua funcionalidade social nas diferentes formas com que se manifesta na sociedade.

Por isso, salientamos que os papéis que as crianças ocuparam na brincadeira influenciaram sobremaneira suas relações com a escrita e os sentidos que a ela atribuíram. Ao modificarem os papéis a serem desempenhados por elas na atividade com a escrita, modificaram-se também os significados desse objeto. Ao ver as crianças experimentando situações que exigiam o uso da escrita devidamente organizada para determinado fim - cumprindo uma função social -, pudemos compreender os caminhos percorridos por elas em sua pré-história da linguagem escrita.

Se na fase inicial o gesto constitui a primeira escrita das crianças, o qual vem acompanhado pelos rabiscos ou garatujas, representando uma imitação do ato da escrita; numa fase posterior, as crianças utilizam o desenho como forma de representar uma ideia, elevando esta forma peculiar de representação, ou seja, convertendo o desenho em signo, pois a história da pré-história da escrita é a história da produção do signo. É o momento em que a criança é capaz de perceber que algo representa algo.

É, portanto, possível e necessário organizar atividades de desenhos e brincadeiras de papéis com a cultura escrita em sua funcionalidade, tais como: escrever para se comunicar, para se orientar, para registrar uma ideia, como meio de identificação, como recurso auxiliar da memória, enfim, como instrumento para significar e interagir no mundo em que as crianças vivem.

A escrita precisa estar presente nas brincadeiras das crianças, não porque as crianças brinquem de escrever, ou que utilizem a escrita de maneira lúdica, mas pelo fato de que na brincadeira de papeis 
sociais a relação das crianças com o objeto escrita se modifica, e elas a significam em consonância com

o papel que assumem, o que lhes possibilita separar o aspecto semântico do material. Esse processo é fundamental para apropriação funcional da escrita na escola de Educação Infantil.

Nota

1 "El hombre, por lo tanto, ha creado um aparato de señales, um sistema de estímulos condicionados artificiales com ayuda de los cuales él crea conexiones artificiales cualesquiera e provoca reacciones necesarias del organismo. Si comparamos, seguiendo a Pavlov, la corteza de los grandes hemisferios con un grandioso cuadro de señales, podríamos decir que el hombre ha creado la lhave de ese cuadro, del grandioso sistema de señales del linguaje. Con ayuda de esa lhave domina desde fuera la actividad de la corteza y dirige el comportamento" (VIGOTSKI, 2000, p. 86-87).

\section{REFERÊNCIAS}

LEONTIEV, A. N. Uma contribuição à teoria do desenvolvimento da psique infantil. In: VIGOTSKI, L. S.; LURIA, A. R.; LEONTIEV, A. N. Linguagem, desenvolvimento e aprendizagem. Tradução de Maria da Penha Villalobos. São Paulo: Ícone, 1988.

LEONTIEV, A. N. Os princípios psicológicos da brincadeira pré-escolar. In: VIGOTSKI, L. S.; LURIA, A. R.; LEONTIEV, A. N. Linguagem, Desenvolvimento e Aprendizagem. Tradução de Maria da Penha Villalobos. São Paulo: Ícone, 1988.

LURIA, A. R. O desenvolvimento da escrita na criança. In: VIGOTSKI, L. S.; LURIA, A. R.; LEONTIEV, A. N. Linguagem, Desenvolvimento e Aprendizagem. Tradução de Maria da Penha Villalobos. São Paulo: Ícone, 1988.

LURIA, A. R. A psicologia experimental e o desenvolvimento infantil. In: VIGOTSKI, L. S.; LURIA, A.R.; LEONTIEV, A. N. Linguagem, Desenvolvimento e Aprendizagem. Tradução de Maria da Penha Villalobos. São Paulo: Ícone, 1988.

MUKHINA, V. Psicologia da idade pré-escolar. Tradução de Claudia Berliner. São Paulo: Martins Fontes, 1995.

VIGOTSKI, L. S. A brincadeira e seu papel no desenvolvimento psíquico da criança. Tradução de Zoia Prestes. Revista Virtual de Gestão de Iniciativas Sociais. Rio de Janeiro, nº 8, jun. 2008.

VIGOTSKI, L. S. A construção do pensamento e da linguagem. Tradução de Paulo Bezerra. São Paulo: Martins Fontes, 2010.

VIGOTSKI, L. S. Obras Escogidas. Tradução de Lydia Kuper. Madrid: Visor, 2000. v. 3. 


\section{Language writing: a history of your pre-history of childhood}

\begin{abstract}
This paper presents part of a study conducted to explain the process of appropriation of written culture by children in early childhood education, according to the organization of writing activities that are afforded to them in the school environment. To understand this process was carried out a pedagogical experiment in a class of children under five years of age, a public school in the city of Uberaba / MG. The theoretical and methodological dimension of this study is based on the principles of human development presented by the HistoricCultural Theory, which brings with it the Activity Theory and the importance of mediation. The proposal of an educational intervention, conducted through the pedagogical experiment, aimed to describe, understand and explain the process of cultural appropriation writing from the day of organized activities in order to create favorable conditions for the development of the process in its constituent features, so that it could provoke and observe the different stages by passing the child in the prehistory of his writing. In outlining the paths taken by it in this process, provided an opportunity the conditions for use of writing in its social functionality, taking advantage of the development activity guide, in this age group, which is the game of social roles. The analysis of the data showed evidence that a pedagogical action, properly planned and mediated, creates conditions that enable the realization of the writing appropriation process in its social functionality, providing a qualitative change in the child's relationship with that kind of language, because she has to write.
\end{abstract}

Keywords: Appropriation of Culture Writing. Play of Social Roles. Writing prehistory. Early Childhood Education.

Ana Maria Esteves Bortolanza

E-mail: amebortolanza@uol.com.br

Selma Aparecida Ferreira da Costa

E-mail:sfc.selma@yahoo.com.br

\section{El lenguaje escrito: una historia de su pre- historia en la infancia}

\section{Resumen}

Este artículo presenta parte de un estudio llevado a cabo para explicar el proceso de apropiación de la cultura escrita por los niños en la educación infantil, de acuerdo con la organización de actividades de escritura que se les concede a ellos en el contexto escolar. Para entender este proceso se llevó a cabo un experimento pedagógico en una clase de niños menores de cinco años de edad, en una escuela pública en la ciudad de Uberaba / Minas Gerais, Brasil. La dimensión teórica y metodológica de este estudio se basa en los principios del desarrollo humano presentados por la Teoría HistóricoCultural, ene special la teoría de la actividad y la importancia de la mediación. La propuesta de una intervención educativa, realizada por médio de la experimentación pedagógica, tuvo como objetivo describir, comprender y explicar el proceso de la apropiación de la cultura escrita a partir de la realización de las actividades organizadas con el fin de crear condiciones favorables para el desarrollo del proceso en sus rasgos constitutivos, para que fuese pçosible provocar y observar las diferentes etapas por las que pasa el niño en la prehistoria de su escritura. Al delinear los caminos recorridos por ella en este proceso, permitió el surgimento de las condiciones de uso de la escritura en su funcionalidad social, utilizando la guía de actividades de desarrollo que en este grupo de edad, es el juego de roles sociales. El análisis de los datos mostró indícios de que una acción pedagógica, debidamente planificada y mediada, crea las condiciones que permiten la realización del proceso de apropiación de la escritura en su funcionalidad social, propiciando un cambio cualitativo en la relación del niño con ese tipo de lenguaje, porque ella presneta la necesidad de escribir.

Palabras claves: Apropiación de la cultura de escritura. Juego de roles sociales. La prehistoria del desarrollo de la escrita. Educación Infantil.

Enviado em: 18/12/2014

Aprovado em: 28/8/2016 